CARDIOLOGY

\title{
Aortic Function: From the Research Laboratory to the Clinic
}

\author{
Konstantinos Dean Boudoulas ${ }^{\text {a }}$ Charalambos Vlachopoulos ${ }^{c}$ Subha V. Raman ${ }^{\text {a }}$ \\ Elizabeth A. Sparks ${ }^{\text {b }}$ Filippos Triposciadis ${ }^{\mathrm{e}}$ Christodoulos Stefanadis $^{\mathrm{b}}$ \\ Harisios Boudoulas ${ }^{\mathrm{a}, \mathrm{d}}$ \\ a Division of Cardiovascular Medicine, The Ohio State University, Columbus, Ohio, and b Johns Hopkins Hospital, \\ Baltimore, Md., USA; ${ }^{C}$ First Department of Cardiology, University of Athens Medical School, and ${ }^{\mathrm{d} B i o m e d i c a l}$ \\ Research Foundation, Academy of Athens, Athens, and 'University of Thessaly Medical School, Larissa, Greece
}

\section{Key Words}

Aortic function - Aortic pain · Pulse wave velocity ·

Reflected waves

\begin{abstract}
For many years, much of the pioneering research on aortic function was carried out by a small group of investigators frequently working away from the clinical environment in the research laboratory. The evaluation of aortic function using aortic pulse wave velocity, aortic distensibility, or other practical indices had yet to reach clinical threshold. It was necessary for the clinicians to take over and to apply these indices to the clinic. In this Odyssey, the work by the basic scientist was important to define the fundamental mechanisms of aortic function; however, it was the vision of the clinical investigator who recognized the importance of aortic function and introduced it into clinical practice. In the near future, the clinical investigator will introduce aortic function in daily clinical practice as the measurement of left ventricular function is used today. A close collaboration between the clinical and the basic investigator will be necessary in order to define the molecular mechanisms related to aortic wall synthesis and degradation of collagen and elas-
\end{abstract}

tin. Application of these findings by the clinical investigator may help to delay or prevent aortic dysfunction related to aging or other conditions and diseases.

Copyright $\odot 2012$ S. Karger AG, Basel

\section{Introduction}

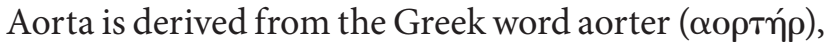
which refers to an umbilical or belt used to hang up the aor $(\alpha \rho \rho)$, the word Homer used for the sword. Aristotle gave to the great vessel the name aorte ( $\alpha$ o $\tau$ r $)$ ), literally something that hangs and carries $[1,2]$. Most likely the original thought was that the purpose of the aorta was to hang the heart. For centuries afterwards, it was believed that the aorta provided a conduit function without other major physiologic properties. It is well appreciated today, however, that the aorta does not only serve as a conduit, but also plays important roles in modulating left-ventricular (LV) performance, myocardial perfusion, central hemodynamics, and arterial function throughout the entire cardiovascular system. All these functions of the aorta influence the circulation in a global fashion [3-9].

\section{KARGER}

Fax +4161306 1234

E-Mail karger@karger.ch

www.karger.com
(C) 2012 S. Karger AG, Basel

0008-6312/12/1211-0031\$38.00/0

Accessible online at:

www.karger.com/crd
Assist. Prof. Konstantinos Dean Boudoulas, MD

Division of Cardiovascular Medicine, Department of Medicine

The Ohio State University

473 W. 12th Avenue, Suite 200, Columbus, OH 43210 (USA)

E-Mail kdboudoulas@osumc.edu 


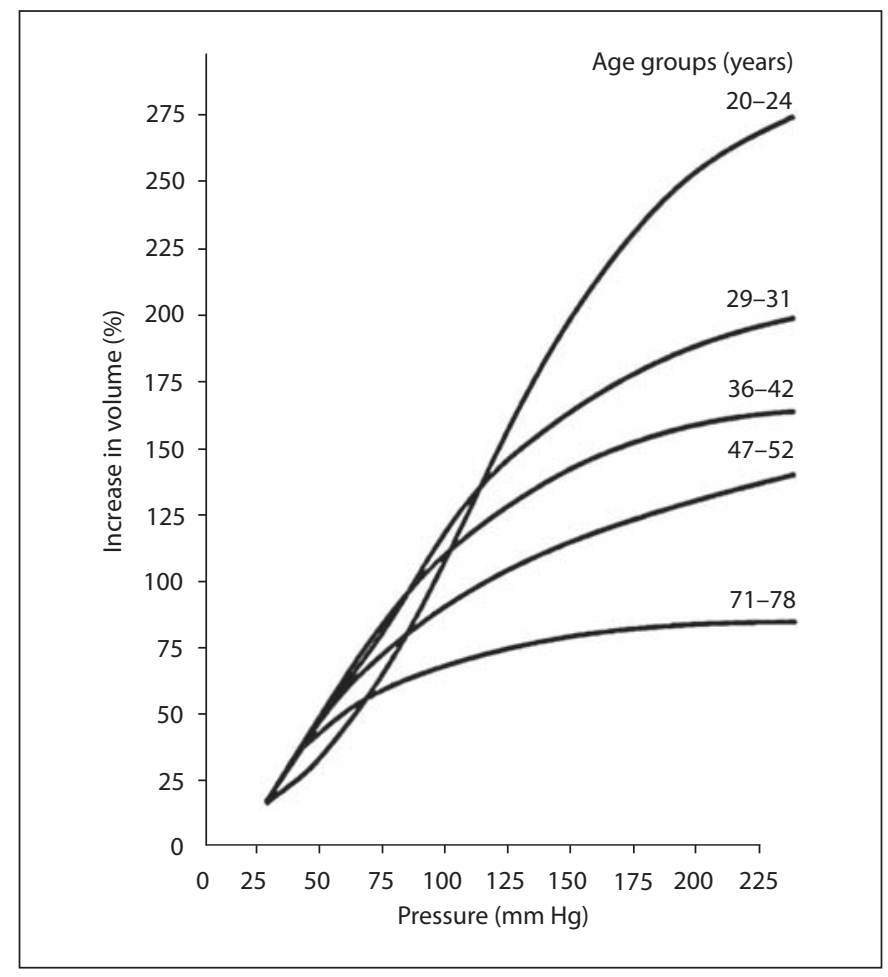

Fig. 1. Pressure-volume relationships for aortas obtained at autopsy from humans in different age groups (see text for details [12]).

\section{Basic Research on Aortic Function}

\section{Basic Concepts of Aortic Function}

For a spring that obeys Hooke's law, the deformation up to a certain point varies in proportion to the applied force: the greater the force the greater the distortion. The same principles that apply to other elastic material apply to the aortic wall, which is elastic as well $[6,7]$. Thus, the stress-strain relationship has been used to estimate the elastic properties of the aorta in tissues obtained from the aortic wall during surgery or autopsy, or from experimental animal models $[10,11]$.

The changes in aortic volume in relationship to the changes in aortic pressure in the entire aorta have been demonstrated originally in aortas obtained from autopsies in various age groups (fig. 1) [12]. All branches of the aorta were ligated and incremental volumes of liquid were injected into this closed system; the internal (aortic) pressure was measured after each increment of volume injected. The relationship between aortic pressure and aortic volume is linear in the younger age group, and this is seen over a wide pressure range; however, this slope de-



Fig. 2. Aortic diameter (AoD; a) and aortic pressure (AoP) recordings (b) [13]. c Electrocardiogram (ECG). d AoP-AoD loops before and $1 \mathrm{~min}$ after diltiazem administration [6].

creases at the upper and the lower ends of the aortic pressure. At any given point, the change in the aortic pressure over the aortic volume represents aortic compliance. The relationship between the aortic pressure and aortic volume changes with age; as age increases, the same aortic pressure produces less changes in the aortic volume. Aortic pressure-aortic diameter loops have been recorded in experimental animals and more recently in humans (fig. 2) $[6,13]$. Although this technique can be easily applied to humans it is not used routinely in clinical practice because it is invasive.

\section{Factors Determining Aortic Function}

The function of the aorta is largely related to the structure of its wall. The normal mammalian aortic wall contains smooth muscle cells, collagen, and elastin. Smooth muscle cell proteins account for approximately $20 \%$ of the dry weight of the media, while collagen and elastin together account for about $60 \%$. There is more elastin than 
collagen in the thoracic aorta and more collagen than elastin in the abdominal aorta. The total amount of elastin plus collagen is approximately the same in all parts of the aorta, and it is constant for adult mammalian aortas $[6,11,14]$.

There is a rich network of innervation and vasa vasorum in the aortic wall of the thoracic aorta, which plays an important role in aortic function. Any change in the structure of the aortic wall may result in a change in the aortic function. Changes in vasa vasorum flow, which is responsible for the perfusion of the outer wall of the thoracic aorta, smooth muscle function, and/or neurohormonal activation, may also affect aortic function $[10,15$, 16].

The pathologic basis for abnormal aortic function has been defined in certain disease states and certain conditions, such as aging, arterial hypertension, atherosclerosis, and heritable connective tissue disorders, for example [17-23].

\section{Evaluation of the Aortic Function}

The determination of the elastic properties of the aorta is based on the changes in the aortic size (volume/diameter) in relation to the changes in the aortic pressure. Further, it is known that the velocity of a material in a tube is related to the elastic properties of the wall of the tube, the diameter of the tube, and the specific gravity of the material, as has been defined by the Moens-Kortweg equation:

$$
\text { Velocity }=\sqrt{\frac{\mathrm{Eh}}{2 \mathrm{pr}}},
$$

where $\mathrm{E}=$ elastic modules; $\mathrm{h}=$ wall thickness; $\mathrm{p}=$ density, and $\mathrm{r}=$ radius.

Thus, the aortic pulse wave velocity (PWV) can be used to estimate the elastic properties of the aorta.

Changes in the aortic pressure in relation to changes in the aortic diameter at any level of the aorta can be used to estimate regional aortic function. Several indices have been used for this purpose, but in our opinion aortic distensibility is more practical and can be calculated using the following formula $[13,14,24]$ :

Aortic distensibility $=2 \times$ (systolic aortic diameter - diastolic aortic diameter)/(diastolic aortic diameter $\times$ pulse pressure) $\mathrm{cm}^{2} \cdot \mathrm{dyn}^{-1} \cdot 10^{-6}$.

Methods most commonly used for the measurements of aortic diameter in systole and diastole are echocar- diography (transthoracic/transesophageal), magnetic resonance imaging (MRI), and contrast aortography. Although there is a difference between the brachial and aortic pressure, a very good correlation was found in estimating aortic distensibility when using aortic pressure and brachial artery pressure measurements [25]; however, because the difference between brachial artery and central aortic pressure may be substantial in certain cases, the gold standard for aortic distensibility measurements should be aortic pressure.

The function of the aorta may vary from region to region because there are regional differences in the structure of the aortic wall [11]. As a general rule, the aorta becomes stiffer as it continues from the aortic root to its bifurcation distally, thus the thoracic aorta is more elastic than the abdominal aorta.

As mentioned above, aortic PWV can be used to estimate aortic function. In contrast to indices based on pressure-diameter changes that only measured regional function of the aorta, the aortic PWV reflects the function of the entire aorta. Hemodynamic consequences of aortic function and dysfunction are directly related to PWV and reflected waves. For this reason, the methods for measuring PWV and reflected waves, and their physiologic significance are presented in more detail $[5,14]$.

\section{PWV-Reflected Waves}

\section{Methods of Measurement}

The time from the beginning of the QRS to the upstroke of the left carotid arterial pulse, and the time from the beginning of the QRS to the beginning of the left femoral arterial pulse are measured (fig. 3) [14, 18]. An alternative method involves the use of Doppler flow velocities of the carotid and femoral arteries in which the beginning of the respective flow velocities are measured $[6,7]$. PWV is calculated as the ratio of the measured distance from the carotid to the femoral artery and to the time required for the Doppler flow signal to travel from the carotid to the femoral artery. There are several commercially available equipments that can be used to measure PWV (Complior, ArCorMedical, Artech Medical, and Sphygmocor). In the future, when aortic function will be used in everyday clinical practice, more equipment will be introduced [14].

When the pulse wave reaches the periphery it returns to the ascending aorta. Normally, the reflecting waves reach the ascending aorta early in diastole, which results in the formation of the diastolic wave. When the elastic 

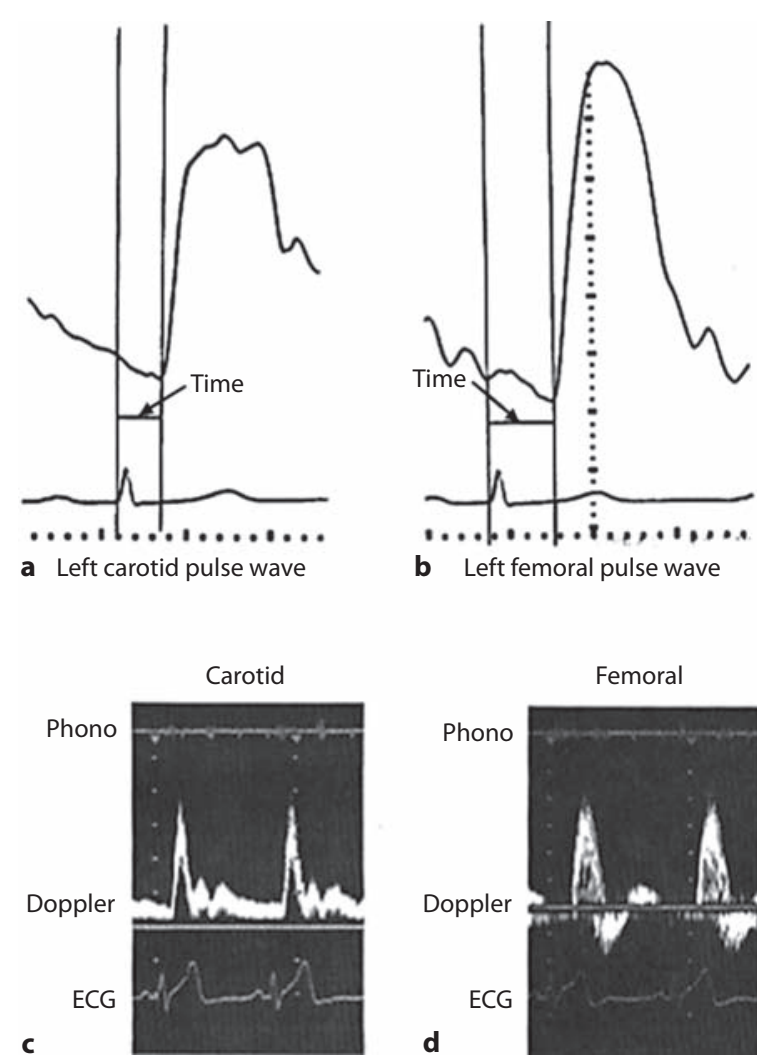

Fig. 3. Carotid (a) and femoral (b) pulses are simultaneously recorded with the electrocardiogram (ECG). Times from the beginning of the QRS complex to the upstroke of the carotid and femoral arteries are shown between perpendicular lines [18]. Doppler flow from the carotid (c) and femoral arteries (d) simultaneously recorded with the ECG. The beginning of flow in both arteries is easily defined and can be used to measure PWV [7].

properties of the aorta are diminished and the PWV is increased, the reflecting waves from the periphery return earlier to the ascending aorta, fuse with the systolic part of the LV resulting in a late systolic peak in the aortic pressure and the disappearance of the diastolic wave [14, $26,27]$.

Analysis of the pulse waveform in the central aorta or in the common carotid artery may provide information related to the reflected waves. The aortic wave form can be estimated non-invasively with applanation tonometry of the radial or the carotid artery. Estimation of the central aortic waveform through tonometry of the radial artery is a widely used technique in clinical practice today. The point where the incident wave merges with the re-

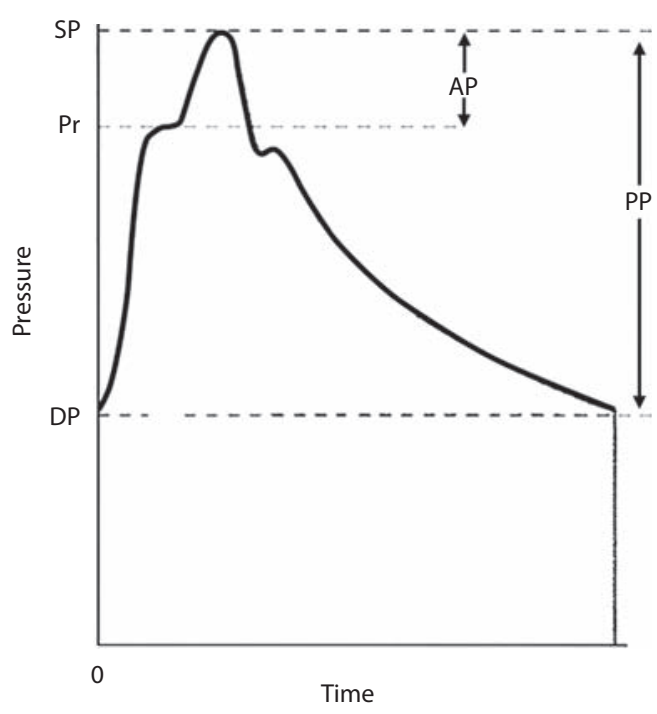

Fig. 4. Schematic presentation of the aortic or carotid artery pressure waveform. Augmentation pressure (AP) is defined as the pressure difference of the late systolic peak (SP) from the pressure at the reflection point (Pr). Augmentation index is the ratio of AP to pulse pressure (PP) derived from the central aortic or carotid pressure [modified from ref. 6]. DP = Diastolic pressure.

flected wave, the reflection point is recognized in the central waveform, and the augmentation pressure, which represents the pressure added to the incident wave by the returning the reflected wave, can be calculated. The augmentation index is an index often used for the estimation of the reflected wave function, and it is calculated as AP divided by the central pulse pressure (fig. 4). Thus, the augmentation index is a composite measure of the magnitude and timing of wave reflections.

The central aortic pulse waveform, however, is influenced by other factors in addition to the stiffness of the aorta, such as the height of the person (length of the aorta), heart rate, and ventricular contractility, just to mention a few $[5,14]$.

\section{Physiologic Significance of PWV and Reflected Waves}

The ejection of blood from the left ventricle during systole generates a pressure wave that is perceived in the periphery as the arterial pulse $[4-7,14]$. The aortic PWV, defined as the speed with which the pulse wave travels in the aorta, is directly related to the elastic properties of the aortic wall. A decrease in the elasticity of the aortic wall causes an increase in PWV, while an increase in aortic wall elasticity causes a decrease in PWV. 


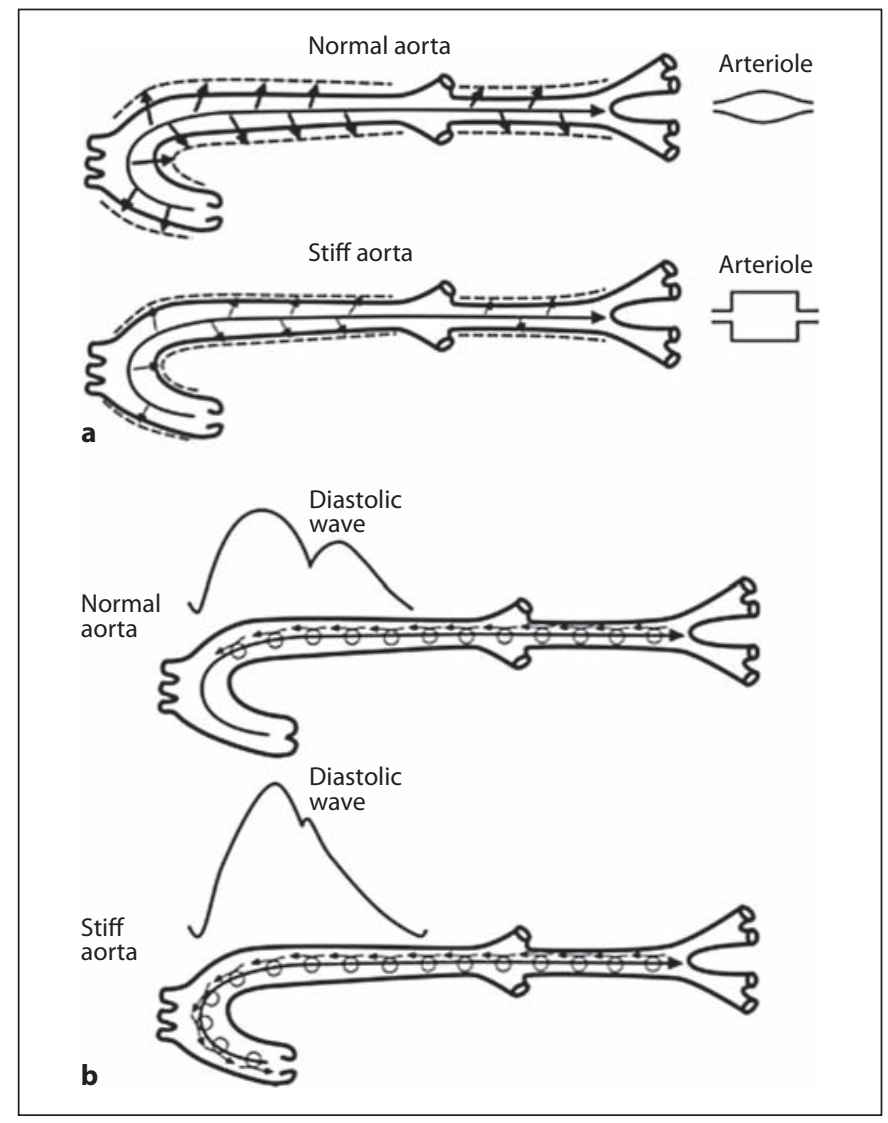

Fig. 5. Aortic function. a Storage capacity, PWV, and arteriolar function: during LV systole, the aorta expands and a large proportion of stroke volume is stored in the aorta. During diastole, aortic pressure is falling. The aorta recoils slowly and the stored blood flows into the periphery. The storage capacity of the aorta is related to its elastic properties; a large proportion of the storage capacity is lost in disease states and with advancing age. PWV is also shown schematically with large arrows. When the aorta is stiff, PWV increases; this results in stretch of the peripheral arterioles and vascular damage. b Reflected wave/aortic pulse wave: the reflected waves are shown schematically. Note that the velocity of reflected waves in the stiff aorta is faster than in the elastic (normal) aorta. The pulse pressure waves of the carotid artery or central aorta in elastic and stiff aortas are also shown (see text for details) [modified from ref. 6, 7].

A fast PWV will result in stretch of the arterioles and vascular damage $[29,30]$. When the elastic properties of the aorta are diminished and the PWV increases, the reflected waves from the periphery return earlier to the ascending aorta, fuse with the systolic part of the pulse wave resulting in a late systolic peak of the systolic pressure, the disappearance of the diastolic wave, and an increase in LV (fig. 5) [6]. Thus, the aortic wave reflections are significant determinants of the central aortic pres-

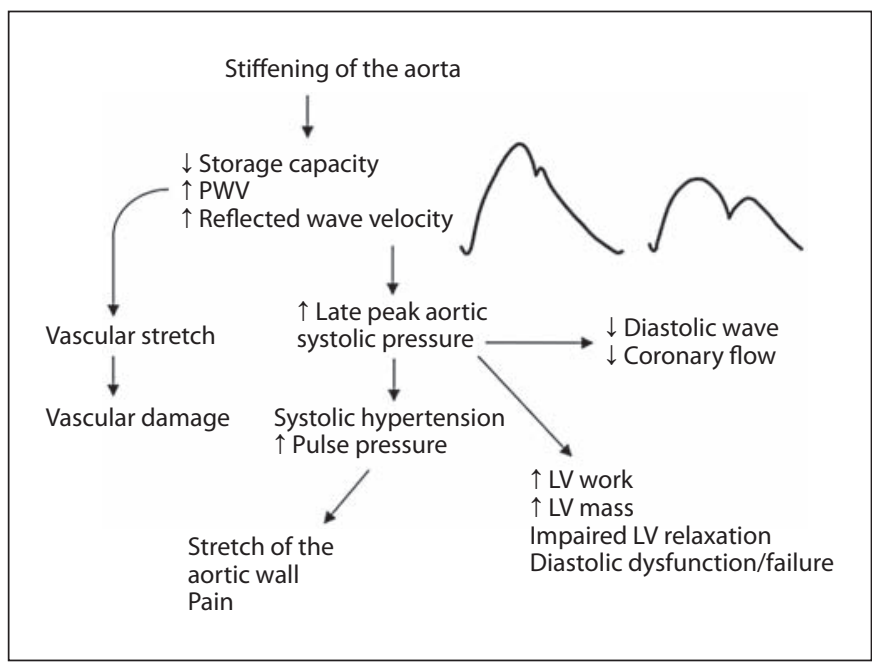

Fig. 6. Effect of aortic dysfunction (aortic stiffening) on the cardiovascular system [modified from ref. 6].

sure. The reflected waves, however, are complex and not as simple as it has been described here. Secondary flow patterns above the aortic valve due to reflected waves have been demonstrated with MRI [7]. Leonardo da Vinci, using his own anatomic and flow structure as the basis, sketched aortic sinus flow patterns with remarkable accuracy in the 16th century [1].

\section{Effects of Aortic Function on the Cardiovascular System}

In a stiff aorta, storage capacity decreases significantly. An increase in PWV will result in an increase in the pulsatile stress in the arterioles and vascular damage, especially in the kidneys and the brain (fig. 6) $[6,29,30]$.

An increase in PWV and reflected wave velocity will result in an increase in systolic aortic pressure, LV work, and LV mass. In the majority of elderly patients, systolic hypertension is related to a stiff aorta. In addition, LV relaxation will be impaired resulting in diastolic LV dysfunction and diastolic heart failure. Thus, a stiff aorta is a major factor contributing to pathophysiologic mechanisms related to heart failure in patients with preserved LV ejection fraction. In addition, patients with a stiff aorta will have reduced coronary flow due to a decrease in the diastolic aortic pressure, and a decrease or disappearance of the diastolic wave $[6,14]$. Further, a stiff aorta may produce chest pain, the mechanisms of which are discussed in the next section. 


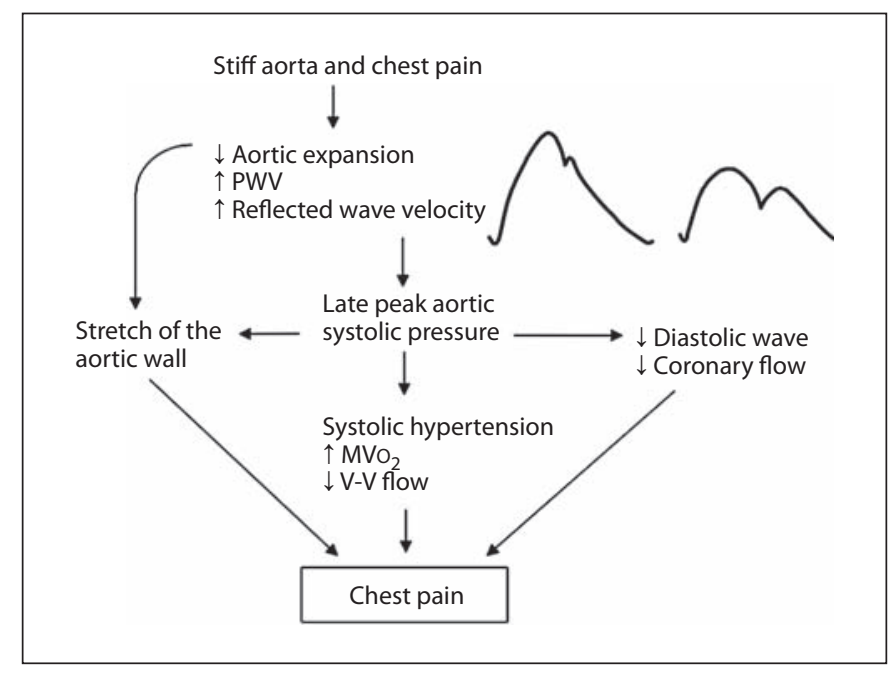

Fig. 7. Possible mechanisms of chest pain in patients with a stiff aorta (see text for details). $\mathrm{MVO}_{2}=$ Myocardial oxygen consumption; $\mathrm{V}-\mathrm{V}=$ vasa vasorum.

\section{Chest Pain of Aortic Origin: The Aortic Pain Syndrome}

Increased aortic stiffness may result in chest pain that may be produced by several mechanisms [1]. A sudden rise in aortic systolic pressure during exercise or any other stress in a less expandable aorta may produce an increased stretch of the aortic wall. This stretch stimulates aortic pain fibers and produces chest pain (fig. 7). Clinical and experimental observations suggest that forced stretch of the aortic wall may produce chest pain. Balloon inflation during angioplasty for aortic coarctation causes pain that disappears immediately after balloon deflation. The aortic adventitia contains pain fibers that are in close relation to those of the heart. Acute stretching of the aortic wall or coating the aorta with irritants stimulates pain fibers and produces pain $[1,6]$. Further, an increase in aortic stiffness is associated with systolic hypertension resulting in an increase in myocardial oxygen consumption. A sudden increase in systolic pressure may result in a decrease in the vasa vasorum flow, which perfuses the aortic wall, resulting in chest pain of aortic origin $[6,7]$. In addition, systolic hypertension is associated with a decrease in diastolic aortic pressure, which may decrease coronary flow. Due to the diminished or disappearance of the diastolic wave in the central aortic pressure, coronary blood flow is further compromised. All these factors may lead to subendocardial ischemia, especially when LV hypertrophy is present. In addition, a stiff aorta is associ- ated with impaired myocardial microcirculatory function and decreased coronary flow reserve. Thus, chest pain of aortic origin may be a common phenomenon. Chest pain of aortic origin may exist even in patients with coronary artery disease since those patients also have a stiff aorta. In other diseases or conditions often associated with a stiff aorta, such as chronic renal disease, older age, and diabetes mellitus, chest pain of aortic origin may also exist [6].

\section{Definition of Aortopathy, Prognostic Significance of Aortic Dysfunction, and Interventions That May Alter Aortic Function}

A man is as old as his arteries

Thomas Sydenham

(1624-1689)

Aortopathy unites the Greek word aorte, the great artery, with the word pathy (termination) derived from pathos which denotes a morbid condition or disease $[1,2]$. The resulting descriptive term refers to any disease of the aorta.

Traditionally, the diagnosis of aortic wall disorders has been dependent upon the recognition of the complications of the aortopathic process such as aortic dilatation, dissection, thrombosis, or rupture, and highly dependent on the technology of the era for confirmation of the complication. Until recently, there have been no clinically useful diagnostic procedures for the detection of diseases of the aortic wall prior to the development of these gross morphologic changes $[1,6]$. For this reason, the detection of functional disorders of the aorta has been introduced. Today, it is well known that an anatomically 'normal' aorta as defined by imaging techniques (echocardiography, computed tomography, or MRI) functionally may be grossly abnormal $[6,7,14]$. It should be emphasized that aortic function has to be determined to define an abnormal aorta. Abnormal aortic function is present in many conditions and diseases, and it is associated with a higher incidence of cardiovascular events compared to a normally functioning aorta (table 1). In addition, heritable connective tissue disorders, multifactorial diseases (e.g. arterial hypertension or coronary artery disease), and environmental factors may alter aortic function acutely (i.e. cold or stress) or on a chronic basis. The elastic properties of the aorta diminish with age in apparently 'healthy' individuals and furthermore in conditions/diseases associated with aortic dysfunction [27, 31-70]. 
Table 1. Conditions and diseases associated with abnormal aortic function

Heritable connective tissue disorders/congenital heart disease
Marfan syndrome
Smooth muscle $\alpha$-actin mutation $\left(\mathrm{ACTA}_{2}\right)$
Ehlers-Danlos syndrome
Annuloaortic ectasia
Adult polycystic kidney disease
Bicuspid aortic valve
Coarctation of the aorta
Tetralogy of Fallot
Heritable metabolic disorders
Thalassemia major
Other
Multifactorial diseases
Atherosclerosis
Arterial hypertension
Diabetes mellitus
Chronic renal disease
Collagen diseases
Other
Environmental factors
Aortitis, infective/inflammatory disease (Takayasu, syphilis)
Smoking
Diet, obesity
Lack of exercises
Mental stress
Drugs-toxins
Physical factors (cold)
Other
Aging

Table 2. Factors which may alter aortic function

\author{
Environment \\ Pharmacologic agents \\ Nitrates \\ Angiotensin-converting enzyme inhibitors \\ Angiotensin receptor blockers \\ Statins \\ Calcium channel blockers \\ Diuretics \\ $\beta$-Adrenergic receptor blockers \\ Anti-diabetic drugs (glipizide, metformin, troglitazone) \\ Parasympathetic denervation
}

Determination of the elastic properties of the aorta may help to monitor the natural history of a disease process. Experimental studies have shown that histologic changes in the arterial wall during the development and regression of atherosclerosis, and during the develop-
Table 3. Aortic function: a strong prognostic indicator for cardiovascular events in the following conditions/diseases/groups

Arterial hypertension

Coronary artery disease

Diabetes mellitus

Chronic renal disease

Mitral/aortic regurgitation

Elderly population

Apparently 'healthy' individuals

Other

ment and treatment of arterial hypertension were parallel to the changes in indices reflecting aortic function [6].

Different therapeutic interventions, including pharmacologic agents, may alter the elastic properties of the aorta (table 2) [71-86]. Several long-term studies have shown that aortic stiffness may independently predict cardiovascular morbidity and mortality (table 3) [27, 64]. $\mathrm{PWV}$, a simple index related to the function of the entire aorta, can stratify patients in different risk groups for future cardiovascular events; this was initially shown in high-risk patients with end-stage renal disease, but several other studies have shown that an increase in PWV may predict adverse outcomes in patients with risk factors such as arterial hypertension, diabetes mellitus, and even apparently 'healthy' individuals [27, 64]. For these reasons, the guidelines of the 2007 European Society of Hypertension/European Society of Cardiology for the management of arterial hypertension concluded that determination of PWV may be used for better patient stratification $[87,88]$.

\section{The Role of MRI in the Evaluation of the Aorta}

MRI affords not only precise delineation of the aortic anatomy but is also uniquely suited to interrogate aortic function. Its advantages over other modalities to assess the dynamic aorta include (1) sufficient spatial and temporal resolution to distinguish small and rapid changes in the aorta; (2) ability to localize physiologic measures to individual segments along the entire aorta, and (3) lack of ionizing radiation. Disadvantages compared to other modalities include intolerability for a small percentage of individuals with recalcitrant claustrophobia, and relatively limited availability of technology and expertise. In appropriate centers and suitable patients, MRI provides unparalleled functional assessment of the aorta. 
Fig. 8. Routine cine magnetic resonance obtained in an axial plan perpendicular to the mid-ascending aorta provides end-systolic and end-diastolic frames from which the aortic cross-sectional area can be measured. The same region of interest (- - ) around the ascending aorta at end-systole is pasted on the end-diastolic frame with little change in the cross-sectional area, consistent with poor aortic distensibility in this patient treated for hypertension. $\mathrm{PA}=$ Pulmonary artery.

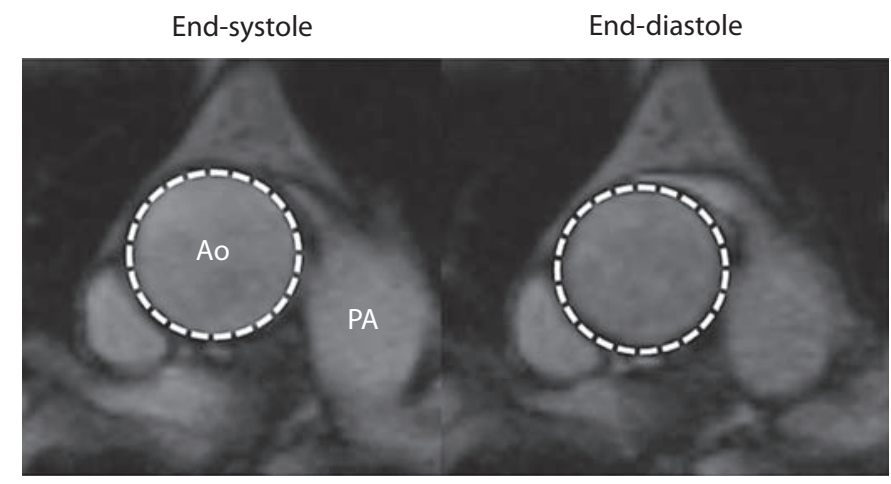

Fig. 9. Phase-contrast cine magnetic resonance is shown acquired in an oblique sagittal plane along the aorta. Magnitude and velocity-encoded images demonstrate aortic anatomy and velocities at each point along the aorta, from which aortic PWV can be computed.

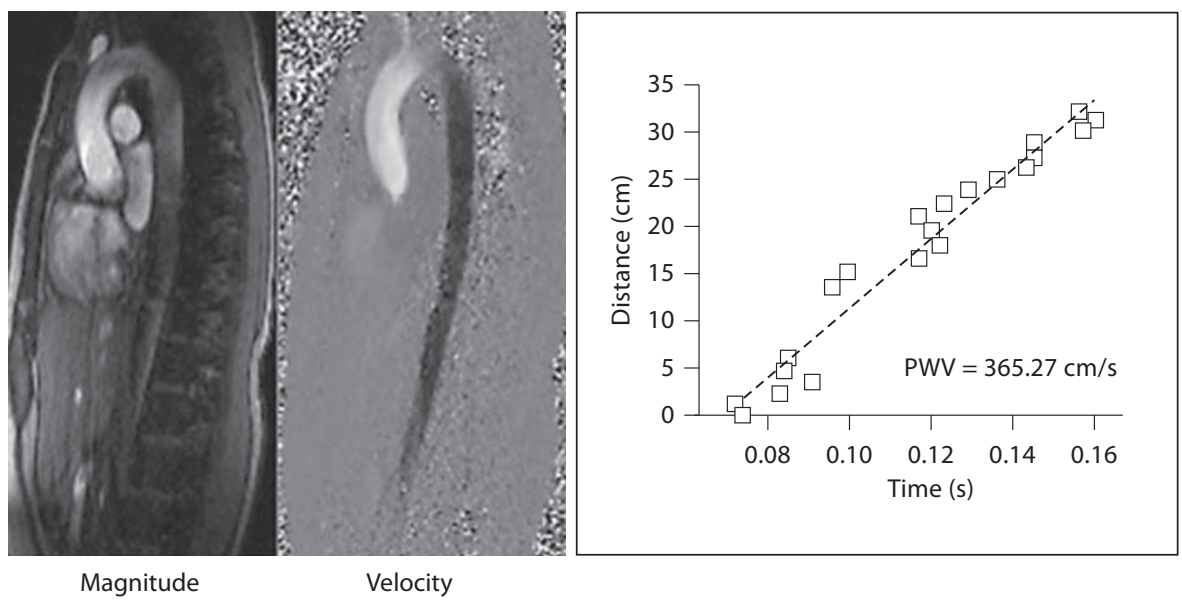

Comparison of an aortic cross-section between endsystole and end-diastole was one of the earliest MRI techniques used to evaluate aortic function [89]. This technique remains in use today, albeit with more rapid and higher resolution (fig. 8), as a straightforward method to measure aortic distensibility. Underscoring the connection between aortic compliance and afterload faced by the left ventricle, reduced aortic distensibility occurs in older healthy compared to younger healthy individuals, and is further reduced in patients with diastolic heart failure [90, 91]. Aortic distensibility has also been used to identify early changes in the aorta in patients with heritable aortopathies such as the Marfan syndrome, providing additional predictive value beyond baseline aortic diameter for aortic dilatation [92]. Dynamic MRI has been used to demonstrate measurable abnormalities in systolic distension and diastolic recoil of the ascending aorta in conditions such as bicuspid aortic valve [93].

More sophisticated measures of aortic function include PWV (fig. 9), thought to represent a relatively loadindependent parameter compared to aortic distensibility that requires pulse pressure for calculation. Several MRI techniques have been developed to compute aortic PWV; the simplest use cross-sectional velocity encoding or phase-contrast acquisitions at a proximal and distal segment, and PWV is computed as the distance between segments divided by the time delay for appearance of the foot of the aortic pulse wave between the more distal versus the more proximal segment. More sophisticated approaches that directly encode PWV have recently been used to confirm age-related changes in aortic stiffness [94]. While hand-held applanation tonometry also yields PWV measurements and affords significant advantages over MRI in terms of cost and deployment across various clinical and investigative settings, simultaneous and direct interrogation of multiple regions of the aorta with MRI-based PWV may be beneficial for some applications.

Four-dimensional flow visualization (three anatomic dimensions plus time) is now feasible over the entire aorta with suitable post-processing and rendering software. One quantitative measure that results from such acquisi- 
tions is aortic wall shear stress, with regional variations in healthy individuals suggesting why certain sites may be more prone to develop atherosclerosis [95]. By coupling aortic and cardiac flow measurements with such techniques [96], there is much to be learned about the interplay between aortic function and cardiovascular disease.

\section{Aortic Function: Concluding Remarks}

The history of aortic function begins with the determination of arterial pulse, which clinicians have used from antiquity. Measurement of the arterial pressure by sphygmomanometry introduced at the beginning of the last century by Nikolai Korotkoff provided another indirect index of aortic function [2, 6]. Bramwell and Hill [97, 98] described an increase in arterial PWV in 1922. Ascending aortic impedance (directly related to aortic function) was introduced by McDonald $[99,100]$ in the middle of the last century to describe the hydraulic load presented to the intermittently pumping LV to the systemic circulation. Aortic impedance determination, however, requires relatively speaking complex calculations using mathematical formulas that are not practical for everyday clinical use [101].

Aortic Function - Lost in Translation: For many years, much of the pioneering research on aortic function was carried out by a small group of investigators frequently working away from the clinical environment and in the research laboratories; the evaluation of aortic function using aortic $\mathrm{PWV}$, aortic distensibility, or other practical indices had yet to reach a clinical threshold $[99,100,102$, 103]. It was necessary for the clinicians to take over and to apply these indices to the clinic. In our opinion, the First International Conference on Functional Abnormalities of the Aorta, which was organized by the First De- partment of Cardiology, University of Athens, Greece, and the Division of Cardiology, The Ohio State University, Columbus, Ohio, USA, on October 25th-26th, 1993, in Athens [P. Toutouzas, C. Stefanadis, C.F. Wooley, and H. Boudoulas], had contributed significantly to the translation of aortic function from the bench to the clinic. At this point, the pioneering work by Michael O'Rourke and Michel Safar should be acknowledged.

In this Odyssey, the work by basic scientists was important to define the fundamental mechanisms of aortic function; however, it was the vision of the clinical investigator who recognized the importance of aortic function and introduced it into clinical practice. It was the clinical investigator who defined that aortic function is not only important for LV performance, but also for the function of the entire cardiovascular system $[6,7,104,105]$. It was the clinical investigator who defined that abnormal elastic properties of the aorta may precede the clinical manifestations of a disease and that changes in the elastic properties of the aorta may be parallel to the progression or regression of a disease process. It was the clinical investigator who also defined the effect of pharmacologic and non-pharmacologic interventions on aortic function [5-7]. In the near future, the clinical investigator will introduce aortic function in daily clinical practice and it will be used as the measurement of LV function is used today. The clinical investigator will define the effect of intra-aortic devices, especially in young patients, on PWV [106].

A close collaboration between the clinical and the basic investigator will be necessary in order to define the molecular mechanism(s) related to aortic wall synthesis, and degradation of collagen and elastin. Applications of these findings by the clinical investigator in the clinic will result in a delay or even prevention of aortic dysfunction related to aging or other conditions and diseases.

\section{References}

1 Wooley CF, Sparks EA, Boudoulas H: Aortic pain: the renaissance of cardiovascular pain and the detection of aortopathy. Herz 1999; 24:140-153.

2 Wooley CF, Silverman ME: Historical perspectives: the aorta in time; in Boudoulas $\mathrm{H}$, Stefanadis C (eds): The Aorta: Structure, Function, Dysfunction, and Diseases. New York, Informa Healthcare USA, 2009, pp 1-6.

3 Nichols WW, O'Rourke MF: McDonald's Blood Flow in Arteries. London, Arnold, 2005 .
-4 O'Rourke MF, Staessen JA, Vlachopoulos C, et al: Clinical applications of arterial stiffness: definitions and reference values. Am J Hypertens 2002; 15:426-444.

5 Nichols WW, O’Rourke MF, Vlachopoulos C (eds): McDonald's Blood Flow in Arteries: Theoretical, Experimental and Clinical Principles, ed 6. London, Hodder Arnold, 2011.

6 Boudoulas H, Stefanadis Ch: The Aorta: Structure Function, Dysfunction and Diseases. New York, Informa Healthcare, 2009.
7 Boudoulas H, Toutouzas PK, Wooley CF: Functional Abnormalities of the Aorta. Armonk, Futura, 1996.

8 Zamorano J, Erbel R, Boudoulas H: Aortic Function and Diseases. Madrid, Aran, 1998.

9 O'Rourke MF: Arterial Function in Health and Disease. Edinburgh, Churchill Livingstone, 1982. 
10 Angouras D, Sokolis DP, Dosios, et al: Effect of impaired vasa vasorum flow on the structure and mechanics of the thoracic aorta: implications for the pathogenesis of aortic dissection. Eur J Cardiothorac Surg 2000;17: 468-473.

-11 Sokolis DP, Boudoulas H, Karayannakos PE: Segmental differences of aortic function and composition: clinical implications. Hell J Cardiol 2008;49:145-154.

12 Hallock P, Benson IC: Studies on the classic properties of human isolated aorta. J Clin Invest 1937;20:595-602.

-13 Stefanadis C, Stratos C, Vlachopoulos C, Marekas, Boudoulas H, et al: Pressure-diameter relation of the human aorta. A new method of determination by the application of a special ultrasonic dimension catheter. Circulation 1995;92:2210-2219.

14 Vlachopoulos C, Aznaouridis K, Stefanadis C, Boudoulas H: Aortic function: methods of evaluation; in Boudoulas H, Stefanadis C (eds): The Aorta: Structure, Function, Dysfunction, and Diseases. New York, Informa Healthcare, 2009, pp 41-59.

-15 Stefanadis C, Karayannacos PE, Boudoulas $\mathrm{H}$, Stratos C, et al: Medial necrosis and acute alterations in aortic distensibility following removal of the vasa vasorum of canine ascending aorta. Cardiovasc Res 1993;27:951956.

-16 Stefanadis C, Vlachopoulos C, Karayanna$\cos \mathrm{P}$, Boudoulas $\mathrm{H}$, et al: Effects of vasa-vasorum flow on structure and function of the aorta in experimental animals. Circulation 1995;91:2669-2678.

17 McGrath BP, Liang YL, Teede H, et al: Agerelated deterioration in arterial structure and function in postmenopausal women: impact of hormone replacement therapy. Arterioscler Thromb Vasc Biol 1998;18:11491156.

18 Hirata K, Triposkiadis F, Sparks EA, Bowen J, Wooley CF, Boudoulas H: The Marfan syndrome: abnormal elastic properties. J Am Coll Cardiol 1991;18:57-63.

- 19 Pepin M, Schwarze U, Superti-Furga A, Byers $\mathrm{PH}$ : Clinical and genetic features of Ehlers-Danlos syndrome type IV, the vascular type. N Engl J Med 2000;342:673-680.

20 Sokolis DP, Lambropoulos KM, Dimitrio EH, Papalouka V, Balafas E, et al: Geometri$\mathrm{cal}$ and structural changes of the rat aorta following chronic beta-blocker treatment. Ann Biomed Eng, submitted.

21 Boudoulas H, Wooley CF: Aortic function. J Heart Valve Dis 1998;7:54-58.

22 Al-Mallah MH, Nasir K, Katz R, et al: Thoracic aortic distensibility and thoracic aortic calcium (from the Multi-Ethnic Study of Atherosclerosis). Am J Cardiol 2010;106: 575-580.

23 Sokolis DP, Mitropoulos F, Perree D, et al: Pulse wave velocity in the progression of experimentally induced atherosclerosis in rabbits. J Noninvasive Cardiol 1998;2:8-13.
4 Stefanadis C, Wooley CF, Bush CA, Kolibash AJ, Boudoulas H: Aortic distensibility abnormalities in coronary artery disease. Am J Cardiol 1987;59:1300-1304.

25 Stefanadis C, Stratos C, Boudoulas H, Kourouklis C, Toutouzas P: Distensibility of the ascending aorta: comparison of invasive and non-invasive techniques in healthy men and in men with coronary artery disease. Eur Heart J 1990;11:990-996.

26 Agabiti-Rosei E, Mancia G, O’Rourke MF, et al: Central blood pressure measurements and antihypertensive therapy: a consensus document. Hypertension 2007;50:154-160.

27 Vlachopoulos C, Aznaouridis K, Stefanadis C: Prediction of cardiovascular events and all-cause mortality with arterial stiffness: a systematic review and meta-analysis. J Am Coll Cardiol 2010;55:1318-1327.

28 Cavalcante JL, Lima JAC, Redhenil A, AlMallah MH: Aortic stiffness: current understanding and future directions. J Am Coll Cardiol 2011;57:1511-1522.

29 Safar ME, London GM, Plante GE: Arterial stiffness and kidney function. Hypertension 2004;43:163-168.

30 O’Rourke MF, Safar ME: Relationship between aortic stiffening and microvascular disease in brain and kidney: cause and logic of therapy. Hypertension 2005;46:200-204.

31 Grotenhuis HB, Ottenkamp J, Westenberg JJ, Bax JJ, Kroft LJ, et al: Reduced aortic elasticity and dilatation are associated with aortic regurgitation and left ventricular hypertrophy in nonstenotic bicuspid aortic valve patients J Am Coll Cardiol 2007;49:16601665.

32 Mattace-Raso FU, van der Cammen TJ, Hofman A, et al: Arterial stiffness and risk of coronary heart disease and stroke: the Rotterdam Study. Circulation 2006;113:657663.

33 Nistri S, Grande-Allen J, Noale M, et al: Aortic elasticity and size in bicuspid aortic valve syndrome. Eur Heart J 2008;29:472-479.

-34 Chong WY, Wong WH, Chiu CS, Cheung YF: Aortic root dilation and aortic elastic properties in children after repair of tetralogy of Fallot. Am J Cardiol 2006;97:905-909.

- 35 Al Mheid I, Patel R, Murrow J, Morris A, Rahman A, et al: Vitamin D status is associated with arterial stiffness and vascular dysfunction in healthy humans. J Am Coll Cardiol 2011;58:186-192.

36 Heesen WF, Beltman FW, Smit AJ, et al: Reversal of pathophysiologic changes with long-term lisinopril treatment in isolated systolic hypertension. J Cardiovasc Pharmacol 2001;37:512-521.

37 Erol MK, Yilmaz M, Oztasyonar Y, Sevimli $\mathrm{S}$, Senocak H: Aortic distensibility is increasing in elite athletes. Am J Cardiol 2002;89: 1002-1004.

38 Vaitkevicius PV, Fleg JL, Engel JH, et al: Effects of age and aerobic capacity on arterial stiffness in healthy adults. Circulation 1993; 88:1456-1462.
39 Vlachopoulos C, Alexopoulos N, Boudoulas $\mathrm{H}$, Stefanadis C: Aortic function in coronary artery disease; in Boudoulas $\mathrm{H}$, Stefanadis $\mathrm{C}$ (eds): The Aorta: Structure, Function, Dysfunction and Diseases. New York, Informa Healthcare, 2009, pp 88-95.

40 Kullaras K, Sparks EA, Schuster DP, Osei K, Wooley CF, Boudoulas H: Cardiovascular effects of aging. Inter-relationships of aortic, left ventricular, and left atrial function. Herz 2001;26:129-139.

41 Hashimoto J, O’Rourke MF: Basic concepts of regulation of aortic function; in Boudoulas H, Stefanadis C (eds) The Aorta: Structure, Function, Dysfunction, and Diseases. New York, Informa Healthcare, 2009, pp 22 30.

42 Vlachopoulos C, Alexopoulos N, Boudoulas $\mathrm{H}$, Stefanadis C: Aging and aortic function; in Boudoulas H, Stefanadis C (eds): The Aorta: Structure, Function, Dysfunction, and Diseases. New York, Informa Healthcare, 2009, pp 64-70.

43 Brili S, Gatzoulis M, Stefanadis Ch, Boudoulas $\mathrm{H}$ : Aortic function in congenital heart disease; in Boudoulas H, Stefanadis C (eds): The Aorta: Structure, Function, Dysfunction, and Diseases. New York, Informa Healthcare, 2009, pp 103-108.

44 Stakos DA, Margaritis D, Tziakas DN, Boudoulas $\mathrm{H}$ : Aortic function in beta-thalassemia major; in Boudoulas $\mathrm{H}$, Stefanadis $\mathrm{C}$ (eds): The Aorta: Structure, Function, Dysfunction, and Diseases. New York, Informa Healthcare, 2009, pp 108-112.

45 Sparks EA, Boudoulas H, Wooley CF: Heritable connective tissue disorders: the molecular basis for aortopathy; in Boudoulas $\mathrm{H}$, Stefanadis C (eds): The Aorta: Structure, Function, Dysfunction and Diseases. New York, Informa Healthcare, 2009, pp 113-129.

46 Najjar SS, Scuteri A, Shetty V, et al: Pulse wave velocity is an independent predictor of the longitudinal increase in systolic blood pressure and of incident hypertension in the Baltimore Longitudinal Study of Aging. J Am Coll Cardiol 2008;51:1377-1383.

47 Laurent S, Boutouyrie P, Asmar R, et al: Aortic stiffness is an independent predictor of all-cause and cardiovascular mortality in hypertensive patients. Hypertension 2001; 37:1236-1241.

-48 Laurent S, Katsahian S, Fassot C, et al: Aortic stiffness is an independent predictor of fatal stroke in essential hypertension. Stroke 2003;34:1203-1206.

49 Cruickshank K, Riste L, Anderson SG, Wright JS, Dunn G, et al: Aortic pulse-wave velocity and its relationship to mortality in diabetes and glucose intolerance: an integrated index of vascular function? Circulation 2002;106:2085-2090.

50 Mitchell GF, Hwang SJ, Vasan RS, et al: Arterial stiffness and cardiovascular events: the Framingham Heart Study. Circulation 2010; 121:505-511. 
51 Blacher J, Guerin AP, Pannier B, et al: Impact of aortic stiffness on survival in end-stage renal disease. Circulation 1999;99:2434-2439.

52 London GM, Blacher J, Pannier B, et al: Arterial wave reflections and survival in endstage renal failure. Hypertension 2001;38: 434-438.

53 Guerin AP, Blacher J, Pannier B, et al: Impact of aortic stiffness attenuation on survival of patients in end-stage renal failure. Circulation 2001;103:987-992.

54 Blacher J, Safar ME, Guerin AP, et al: Aortic pulse wave velocity index and mortality in end-stage renal disease. Kidney Int 2003;63: $1852-1860$

-55 Laurent S, Boutouyrie P, Asmar R, et al: Aortic stiffness is an independent predictor of all-cause and cardiovascular mortality in hypertensive patients. Hypertension 2001; 37:1236-1241.

-56 Boutouyrie P, Tropeano AI, Asmar R, et al: Aortic stiffness is an independent predictor of primary coronary events in hypertensive patients: a longitudinal study. Hypertension 2002;39:10-15.

57 Coutinho T, Turner ST, Kullo IJ: Aortic pulse wave velocity is associated with measures of subclinical target organ damage. JACC Cardiovasc Imaging 2011;4:754-761.

58 Matsuoka O, Otsuka K, Murakami S, et al: Arterial stiffness independently predicts cardiovascular events in an elderly community - Longitudinal Investigation for the Longevity and Aging in Hokkaido Country (LILAC) study. Biomed Pharmacother 2005; 59(suppl 1):S40-S44.

-59 Sutton-Tyrrel K, Najjar SS, Boudreau RM, Venkitachalam L, Kupelian V, Simonsick EM, Havlik R, Lakatta EG, Spurgeon H, Kritchevsky S, Pahor M, Bauer D, Newman A, Health ABC Study: Elevated aortic pulse wave velocity, a marker of arterial stiffness, predicts cardiovascular events in well-functioning older adults. Circulation 2005; 111 : 3384-3390.

-60 Willum-Hansen T, Staessen JA, Torp-Pedersen C, et al: Prognostic value of aortic pulse wave velocity as index of arterial stiffness in the general population. Circulation 2006; 113:664-670.

61 Meaume S, Benetos A, Henry OE, et al: Aortic pulse wave velocity predicts cardiovascular mortality in subjects $>70$ years of age. Arterioscler Thromb Vasc Biol 2001;21:20462050.

-62 Shokawa T, Imazu M, Yamamoto H, et al: Pulse wave velocity predicts cardiovascular mortality: findings from the Hawai-Los Angeles-Hiroshima study. Circ J 2005;69:259264.

63 Weber T, Auer J, O’Rourke MF, et al: Increased arterial wave reflections predict severe cardiovascular events in patients undergoing percutaneous coronary interventions. Eur Heart J 2005;26:2657-2663.
64 Vlachopoulos C, Aznaouridis K, O’Rourke MF, Safar ME, Baou K, Stefanadis C: Prediction of cardiovascular events and all-cause mortality with central haemodynamics: a systematic review and meta-analysis. Eur Heart J 2010;31:1865-1871.

-65 Abhayaratna WP, Barnes ME, O’Rourke MF, Gersh BJ, Seward JB, et al: Relation of arterial stiffness to left ventricular diastolic function and cardiovascular risk prediction in patients $\geq 65$ years of age. Am J Cardiol 2006;98:1387-1392.

66 Chirinos JA, Zambrano JP, Chakko S, Veerani A, Schob A, et al: Aortic pressure augmentation predicts adverse cardiovascular events in patients with established coronary artery disease. Hypertension 2005;45:980985.

67 Safar ME, Blacher J, Pannier B, Guerin AP, Marchais SJ, et al: Central pulse pressure and mortality in end-stage renal disease. Hypertension 2002;39:735-738.

68 Thurston H, O’Rourke M, CAFE Investigators: Anglo-Scandinavian Cardiac Outcomes Trial Investigators: CAFE Steering Committee, Writing Committee. Differential impact of blood pressure-lowering drugs on central aortic pressure and clinical outcomes. Circulation 2006;113:1213-1225.

69 Safar M, Blacher J: Aortic and carotid function as a predictor of cardiovascular outcomes; in Boudoulas H, Stefanadis C (eds): The Aorta: Structure, Function, Dysfunction, and Diseases. New York, Informa Healthcare, 2009, pp 71-77.

70 Wilson RA, McDonald RW, Bristow JD, et al: Correlates of aortic distensibility in chronic aortic regurgitation and relation to progression to surgery. J Am Coll Cardiol 1992;19: 733-738.

71 Stacey RB, Bertoni AG, Eng J, Bluemke DA, Hundley WG, et al: Modification of the effect of glycemic status on aortic distensibility by age in the multi-ethnic study of atherosclerosis. Hypertension 2010;55:26-32.

72 Asmar R: Effect of antihypertensive agents on arterial stiffness as evaluated by pulse wave velocity: clinical implications. Am J Cardiovasc Drugs 2001;1:387-397.

73 Benetos A, Vasmant D, Thiéry P, Safar M: Effects of ramipril on arterial hemodynamics. J Cardiovasc Pharmacol 1991;18(suppl 2):S153-S156.

74 Mitchell GF, Dunlap ME, Warnica W, et al: Long-term trandolapril treatment is associated with reduced aortic stiffness: the prevention of events with angiotensin-converting enzyme inhibition hemodynamic substudy. Hypertension 2007;49:1271-1277.

75 Williams B, Lacy PS, CAFE, ASCOT (AngloScandinavian Cardiac Outcomes Trial) Investigators: Impact of heart rate on central aortic pressures and hemodynamics: analysis from the CAFE (Conduit Artery Function Evaluation) study: CAFE-Heart Rate. J Am Coll Cardiol 2009;54:705-713.
6 Williams B, Lacy PS, Cruickshank JK, et al: Impact of statin therapy on central aortic pressures and hemodynamics: principal results of the Conduit Artery Function Evaluation-Lipid-Lowering Arm (CAFE-LLA) study. Circulation 2009;119:53-61.

77 Shige H, Dart A, Nestel P: Simvastatin improves arterial compliance in the lower limb but not in the aorta. Atherosclerosis 2001; 155:245-250.

78 Kontopoulos AG, Athyros VG, Pehlivanidis AN, Demitriadis DS, Papageorgiou AA, Boudoulas H: Long-term treatment effect of atorvastatin on aortic stiffness in hypercholesterolaemic patients. Curr Med Res Opin 2003;19:22-27.

79 Walczewska J, Rutkowski K, Wizner B, Cwynar M, Grodzicki T: Stiffness of large arteries and cardiovascular risk in patients with post-traumatic stress disorder. Eur Heart J 2011;32:730-736

80 Hirata K, Vlachopoulos C, Adji A, O’Rourke MF: Benefits from angiotensin-converting enzyme inhibitor 'beyond blood pressure lowering': beyond blood pressure or beyond the brachial artery? J Hypertens 2005;23: 551-556.

81 Brerthaupt-Gregler, Ling M, Boudoulas M, Balz GG: Protective effect of chronic garlic intake on the elastic properties of the aorta in the elderly. Circulation 1997;96:26492655.

82 Stakos D, Schuster DP, Sparks EA, Wooley CF, Osei K, Boudoulas H: Long-term cardiovascular effects of oral antidiabetic agents in non-diabetic individuals with insulin resistance. Double blind, prospective, randomized study. Heart 2005;91:589-594.

83 Mattace-Raso FU, Hofman A, Verwoert GC, Wittemana JC, Wilkinson I, et al: Determinants of pulse wave velocity in healthy people and in the presence of cardiovascular risk factors: establishing normal and references values. Eur Heart J 2010;31:2338-2350.

84 Vlachopoulos C, Alexopoulos N, Stefanadis C: Aortic function: modification with nonpharmacologic means; in Boudoulas $\mathrm{H}$, Stefanadis C (eds): The Aorta: Structure, Function, Dysfunction, and Diseases. New York, Informa Healthcare, 2009, pp 145-152.

85 Triposkiadis F: Aortic function: modifications with pharmacologic agents; in Boudoulas H, Stefanadis C (eds): The Aorta: Structure Function, Dysfunction, and Diseases. New York, Informa Healthcare, 2009, pp 153-160.

86 Habashi JP, Judge DP, Holm TM, et al: Losar$\tan$, an AT1 antagonist, prevents aortic aneurysm in a mouse model of Marfan syndrome. Science 2006;312:117-121.

87 Mancia G, De Backer G, Dominiczak A, et al: 2007 ESH-ESC Practice Guidelines for the Management of Arterial Hypertension: ESH-ESC Task Force on the Management of Arterial Hypertension. J Hypertens 2007;25: 1751-1762. 
88 Laurent S, Cockcroft J, Van Bortel L, Boutouyrie P, Giannattasio C, et al: Expert consensus document on arterial stiffness: methodological issues and clinical applications. Eur Heart J 2006;27:2588-2605.

89 Mohiaddin RH, Underwood SR, Bogren HG, Firmin DN, Klipstein RH, Rees RS, Longmore DB: Regional aortic compliance studied by magnetic resonance imaging: the effects of age, training, and coronary artery disease. Br Heart J 1989;62:90-96.

90 Hundley WG, Kitzman DW, Morgan TM, Hamilton CA, Darty SN, Stewart KP, Herrington DM, Link KM, Little WC: Cardiac cycle-dependent changes in aortic area and distensibility are reduced in older patients with isolated diastolic heart failure and correlate with exercise intolerance. J Am Coll Cardiol 2001;38:796-802.

-91 Redheuil A, Yu WC, Mousseaux E, Harouni AA, Kachenoura N, Wu CO, Bluemke D, Lima JA: Age-related changes in aortic arch geometry: relationship with proximal aortic function and left ventricular mass and remodeling. J Am Coll Cardiol 2011;58:12621270.
92 Nollen GJ, Groenink M, Tijssen JG, Van Der Wall EE, Mulder BJ: Aortic stiffness and diameter predict progressive aortic dilatation in patients with Marfan syndrome. Eur Heart J 2004;25:1146-1152.

93 Donato Aquaro G, Ait-Ali L, Basso ML, Lombardi M, Pingitore A, Festa P: Elastic properties of aortic wall in patients with bicuspid aortic valve by magnetic resonance imaging. Am J Cardiol 2011;108:81-87.

94 Taviani V, Hickson SS, Hardy CJ, McEniery CM, Patterson AJ, Gillard JH, Wilkinson IB, Graves MJ: Age-related changes of regional pulse wave velocity in the descending aorta using Fourier velocity encoded M-mode. Magn Reson Med 2010;65:261-268.

95 Frydrychowicz A, Stalder AF, Russe MF, Bock J, Bauer S, Harloff A, Berger A, Langer M, Hennig J, Markl M: Three-dimensional analysis of segmental wall shear stress in the aorta by flow-sensitive four-dimensionalMRI. J Magn Reson Imaging 2009;30:77-84.

$\$ 96$ Markl M, Kilner PJ, Ebbers T: Comprehensive $4 \mathrm{D}$ velocity mapping of the heart and great vessels by cardiovascular magnetic resonance. J Cardiovasc Magn Reson 2011;13:7.

97 Bramwell JC, Hill AV: The velocity of the pulse wave in man. Proc Soc Exp Biol Med 1922;93:298-306.

98 Bramwell JC, Hill AV: Velocity of transmission of the pulse wave and elasticity of arteries. Lancet 1922;i:891-892.
99 McDonald DA: The relation of pulsatile pressure to flow in arteries. J Physiol 1955; 127:533-552.

100 McDonald DA, Taylor MG: The hydrodynamics of the arterial circulation. Prog Biophys Chem 1959;9:107-175.

101 Mungo JP, Westerhof N, Giolma JF, et al: Aortic input impedance in normal man: relationship to pressure wave forms. Circulation 1980;62:105-116.

102 Frank O: Der Puls in den Arterien. Z Biol 1905;45:441-553.

103 McDonald DA: Blood Flow in the Arteries, ed 2. London, Arnold, 1974.

104 Nichols WW, Avolio AP, O’Rourke MF: Ascending aortic impedance patterns in the kangaroo: their explanation and relation to pressure waveforms. Circ Res 1986;59:247255.

105 Binkley PF, Boudoulas H: Measurement of myocardial inotropy; in Leier CV (ed): Cardiovascular Drugs: A Clinical Review. New York, Dekker, 1991, pp 5-62.

106 Tzilalis V, Kamvysis D, Panagou P, Kaskarelis I, Lazarides M, Perdikides T, Prassopoulos $\mathrm{P}$, Boudoulas $\mathrm{H}$ : Increased pulse wave velocity and arterial hypertension in young patients with thoracic aortic endografts. Ann Vasc Surg, in press. 